Postgrad. MED. J. (1966), 42, 46

Case Reports

\title{
THYROTOXIC CRISIS AND TRANSIENT MYASTHENIA GRAVIS IN PREGNANCY
}

\author{
P. HORROCKS, M.B., Ch.B. \\ Senior House Officer
}

\author{
J. C. LeONARD, M.D., M.R.C.P. \\ Physician
}

Withington Hospital, Manchester.

WITH safer premedication for thyroidectomy, thyrotoxic crisis is now seldom seen postoperatively. It still occurs, however, when infections or surgical operations complicate uncontrolled thyrotoxicosis, and it is a rare complication of thyrotoxicosis during pregnancy and especially after delivery. We report here a patient who developed a severe thyrotoxic crisis in the ninth month of pregnancy, and whose illness was complicated by transient myasthenia gravis. So far as we can determine, there is no previous record of myasthenia occurring in a thyrotoxic crisis.

\section{Case Report}

The patient, a married woman aged 20 years, was seen early in her first pregnancy by her general practitioner on September 17th, 1963, complaining of nausea, vomiting and dizziness for which triflucperazine was presoribed. A tachycardia was noted then, and her doctor "wondered if she was thyrotoxic". No further action was taken and her pregnancy seemed to make good progress thereafter, although she had gained only $6.4 \mathrm{~kg}$. (14 lb.) by the thirty-sixth week.

She was admitted to Withington Hospital as an emergency on March 24th, 1964. During the previous eight days, she had had severe bilateral throbbing frontal headaches, tiredness and a dry cough. Three days before admission, she developed profuse sweating and rigors; the headaches and fatigue became worse, she vomited twice and felt very ill. On the evening of admission, her temperature had risen to $106^{\circ} \mathrm{F}$. and her pulse rate to $180 / \mathrm{min}$.

On examination at the hospital, she was thin, flushed, apathetic, sweating and very ill; the hands were warm and the temperature was $103.4^{\circ} \mathrm{F}$. There was a marked stare and von Graefe's sign was positive; there was no tremor. The thyroid gland was just palpable, and there was a thrill and a loud continuous murmur over it. The pulse rate was $144 / \mathrm{min}$., B.P. 95/45 mm. Hg., and J.V.P. raised 10 $\mathrm{cm}$. above the sternal angle; no oedema. The heart was hyperdynamic; there was a loud gallop rhythm and a basal ejection systolic murmur conducted to the neck. Examination of the chest was normal. The abdomen contained a gravid uterus consistent with a thirty-six weeks' pregnancy. The tendon reflexes were hyperactive.

Investigations. Hb 8.6 g./100 ml.; WBC 6,500/ cu. mm., normal differential count. The blood urea, serum sodium, chloride and bicarbonate normal; serum potassium $2.95 \mathrm{mEq} / 1$. Chest X-ray normal. ECG: sinus tachycardia. Lumbar puncture: normal CSF normal pressure. A twenty-four-hour specimen of urine contained $250 \mu \mathrm{g}$. of catecholamines. The serological tests for autoimmune thyroiditis were negative. Unfortunately, treatment with iodide was $\overrightarrow{0}$ begun before a specimen of blood for estimation of protein-bound iodine was obtained.

On admission, at 1 a.m. on March 24th, she was gravely ill and a clinical diagnosis of thyrotoxic crisis was made. She was given an intravenous infusion of sodium iodide $1 \mathrm{~g}$. six-hourly in 5 per cent dextrose; she also received phenobarbitone $200 \mathrm{mg}$. त and chlorpromazine $50 \mathrm{mg}$. eight-hourly, Lugol's iodine $10 \mathrm{~min}$. t.d.s., prednisolone $10 \mathrm{mg}$. t.d.s., $\underset{\omega}{\infty}$ reserpine $1 \mathrm{mg}$. t.d.s., carbimazole $20 \mathrm{mg}$. t.d.s. and digoxin. Her condition rapidly improved (see chart), के and ten hours later her temperature was $95.6^{\circ} \mathrm{F}$., and $\frac{\mathrm{O}}{3}$ the pulse rate 104 per minute. After twenty-four hours, sodium iodide was withdrawn for six hours but $\vec{c}$ her condition immediately relapsed; after a further six hours the temperature was $104.2^{\circ} \mathrm{F}$., and the pulse rate 180 per minute. The original dosage of sodium iodide was restored and she again responded; by mid-day on March 25th, the temperature was norma $\overrightarrow{0}$ and the pulse rate 100 per minute. This treatme was continued and after her condition had remained satisfactory for $\mathbf{2 4}$ hours a further attempt was made to reduce the dosage of sodium iodide because off the theoretical risk of acute iodism. At the same time, guanethidine was added in an attempt to suppress the manifestations of thyrotoxicosis. A further deterioration with weakness, cough, fever $\stackrel{\mathbb{Q}}{\varrho}$ and tachycardia again ensued within a few hours $\vec{P}$ of reducing the dosage of sodium iodide and her condition rapidly became alarming. She became 3 semicomatose and a left sixth nerve palsy developed. Within four hours, she developed ptosis, divergent squint, impairment of upward gaze of the eyes, a bilateral lower motor neurone facial palsy, dysphagia, dysarthria and a "myasthenic snarl". $10 \mathrm{mg}$. of edrophonium chloride (Tensilon) was given intravenously and caused a dramatic temporary remission of the myasthenia.

Large doses of sodium iodide were re-introduced intravenously, steroids were gradually withdrawn for fear of exacerbating the myasthenia, neostigmine was given by mouth, and a course of chloramphenicol was given in case an underlying infection was res- o ponsible for precipitating and perpetuating the thyrotoxic crisis. The latter again came under control of within a few hours, but after 24 hours the myasthenia was unchanged. Neostigmine was then added to the $N$ intravenous infusion in a dosage of $7.5 \mathrm{mg}$. (later $N$ 9 mg.) six-hourly; after a further 24 hours there was $\omega$ slow improvement in the neurological signs. Her general condition then began to improve and after 0 two days the thyrotoxicosis was under control and the $\overparen{D}$ myasthenia had been completely suppressed. On $\stackrel{\mathcal{P}}{\rightarrow}$ March 30th, an alarming episode occurred. Whilst talking to a nurse, the patient suddenly lost consciousness and had a generalised tonic convulsion. $\vec{\nabla}$ This was thought to be due to overdosage of neostig- 


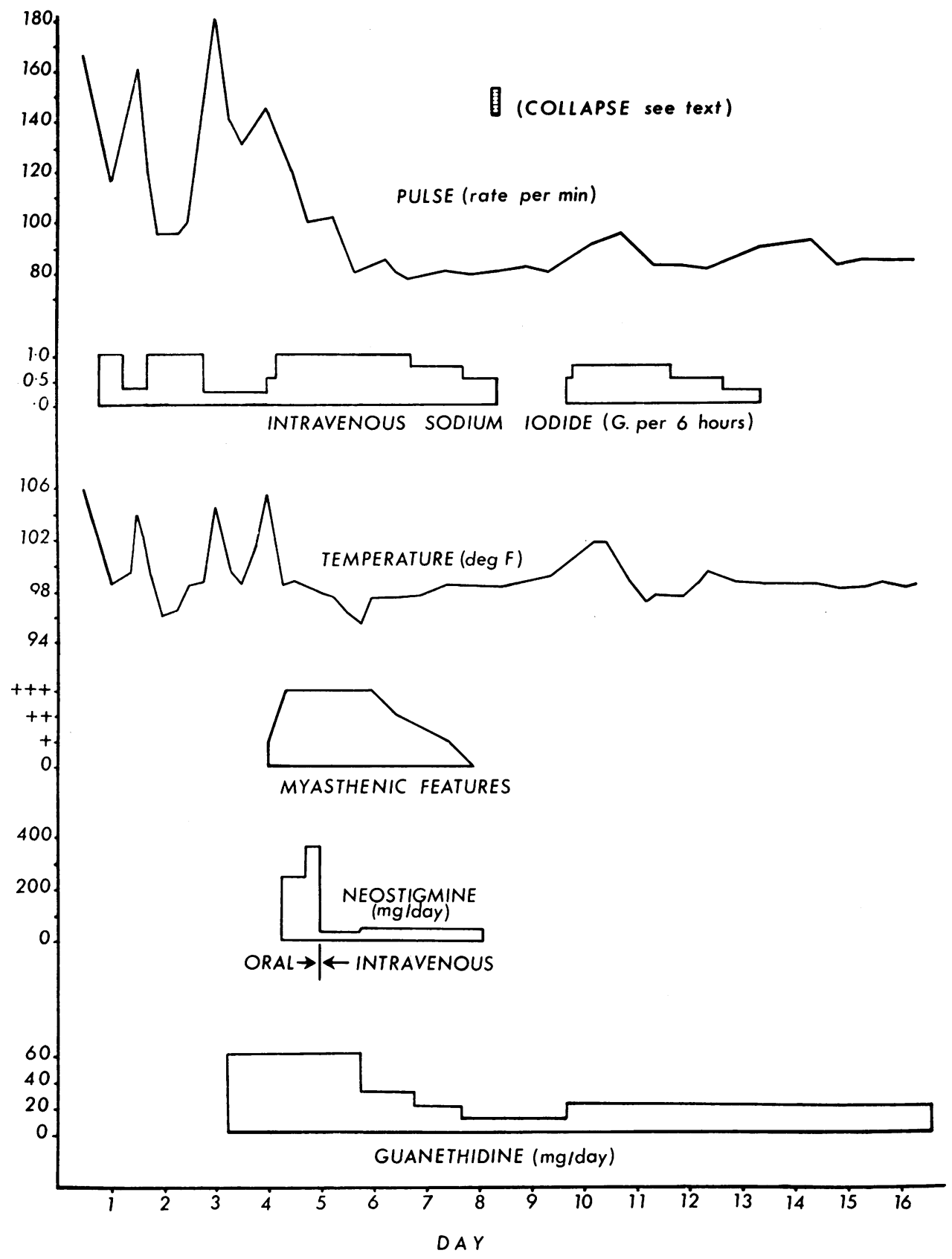

mine, as the patient was still receiving this drug by slow intravenous infusion; the drug was immediately withdrawn and the patient given $0.5 \mathrm{mg}$. of atropine. She gradually recovered consciousness and was apparently no worse for this attack. From then onwards, her progress was rapid: the myasthenia never relapsed and no further neostigmine was required. Intravenous iodide was also withdrawn after this attack, but had to be given two days later in the face of returning fever and tachycardia. It was only after a further four days that intravenous iodide could be finally withdrawn-thirteen days after admission. Throughout this period, the patient had also received carbimazole $20 \mathrm{mg}$. t.d.s., Lugol's iodine $10 \mathrm{~min}$. t.d.s. and digoxin. Reserpine, guanethidine, phenobarbitone and chlorpromazine 
were gradually discontinued. A course of intramuscular iron was given for her anaemia. The thyrotoxicosis was well-controlled and she began to regain some of the weight lost during her illness. By the time she went into labour on April 26th., the patient was taking only carbimazole, Lugol's iodine and digoxin. Labour was uneventful, and the patient was delivered of a healthy girl weighing $6 \mathrm{lbs}$. $3 \mathrm{oz}$. $(2.9 \mathrm{~kg}$.). The infant was clinically normal and made excellent progress. No trouble ensued in the puerperium and Lugol's iodine and digoxin were withdrawn. She was discharged home taking carbimazole $10 \mathrm{mg}$. t.d.s. on May 11 th.

She was seen at frequent intervals in the outpatients' clinic and remained well. The dose of carbimazole was reduced to $10 \mathrm{mg}$. b.d. on August 8th. On September 12th., carbimazole was discontinued and Lugol's iodine substituted. She was re-admitted to hospital on September 29th., and subtotal thyroidectomy was performed by $\mathrm{Mr}$. Alan Nicholson on October 5th. On the next day she developed tetany, and the serum calcium was $7.9 \mathrm{mg}$./ $100 \mathrm{ml}$. She was given seven injections of $10 \mathrm{ml}$. of 10 per cent calcium gluconate during the next two days, and was given calciferol by mouth in gradually decreasing doses. The tetany rapidly subsided and all treatment was discontinued on October 24th. When she was last seen, on May 19th, 1965, she was quite well. The histological report of the thyroid gland was as follows: "There is mild epithelial hyperactivity throughout the gland, but colloid production is abundant; no lymphoid infiltration present. Extra sections have been taken from the posterior aspect of the thyroid lobes but no parathyroid glands have been encountered." (Dr. James Davson.)

\section{Discussion}

In his excellent description of thyrotoxic crisis, Lahey (1928) emphasises that most patients are extremely agitated and nervous, with a marked tremor and often delirium. He recognised, however, that some were very apathetic (as in our case) and similar patients have been reported culminating in thyrotoxic coma (Weaver, Jones and Smith, 1956).

Myasthenia gravis and thyrotoxicosis are known to co-exist more commonly than would be expected by chance, but the nature of the association is very obscure. Sometimes a "seesaw" effect has been described, the myasthenia appearing as the thyrotoxicosis comes under control (Robbins and Burkle, 1960; Monro, 1963). Weickhardt and Redmond (1960) throw doubt on this and point out that sometimes myasthenia may appear when the patient is severely thyrotoxic, as in our own case. It is clear from published cases only that there is no constant pattern. One factor which may have operated in our own patient is that the myasthenia followed large doses of chlorpromazine, which is thought sometimes to precipitate weakness in a myasthenic patient. (McQuillan, Gross and Johns, 1963).

Our patient was given so many different agents during the height of her illness that it may be thought difficult to identify those that were therapeutically most useful. The management of thyrotoxic crisis in recent years has been improved by the introduction of chlorpromazine, and pos- $\frac{3}{8}$ sibly also by corticosteroids, guanethidine and $\stackrel{2}{2}$ reserpine; the latter two drugs are useful in $ᄃ$ suppressing the peripheral manifestations of thy- $\overrightarrow{\vec{F}}$ rotoxicosis whilst not curing the disease. $\stackrel{5}{+}$ Corticosteroids are advised because of the possibility of adrenocortical exhaustion in thyrotoxic $\overline{\text { 을 }}$ crisis. In spite of the use of all these drugs, $\frac{\bar{\rho}}{\frac{}{\sigma}}$ however, it was our distinct impression that intra- $\bar{D}$ venous sodium iodide was by far the most effective agent in the management of our patient. ${ }^{\infty}$ We repeatedly observed that increasing the con- $\overrightarrow{0}$ centration of iodide in the infusion quickly led to reduction in fever and tachycardia, whilst both $\vec{\omega}$ relapsed whenever iodide was discontinued. A daily dose of $4 \mathrm{~g}$. of iodide was tolerated withoutco evidence of ill effect (see chart).

It is therefore suggested that in the management of thyrotoxic crisis, intravenous sodium iodide should be given in a dosage of at least $\underset{\omega}{\infty}$ $0.5 \mathrm{~g}$. six-hourly. Reductions in the dose should be made cautiously, and the dose increased if $\vec{\circ}$ fever and tachycardia return or are uncontrolled. 의 The patient should be nursed in an oxygen tent; skilled nursing care and observation are essential. $\stackrel{c}{a}$ Hyperpyrexia and restlessness should be controlled by chlorpromazine, tepid sponging and phenobarbitone. Intravenous hydrocortisone should $₹$ also be given. Guanethidine and reserpine m\& $\overrightarrow{0}$ be used for their symptomatic value. A caref $\stackrel{\circ}{\circ}$ search must be made for any precipitating id fection, and appropriate treatment institute Heart failure must be controlled by digoxin; the value of propranolol in severe thyrotoxicosis is currently being assessed. Carbimazole should be started immediately, but will not have much $\stackrel{\square}{\triangle}$ therapeutic effect for two weeks.

\section{Summary}

A woman who developed a thyrotoxic crisis in the ninth month of pregnancy is described. At the height of her illness, she developed neostig- $-\overrightarrow{0}$ mine-responsive myasthenia lasting four days. 3 The management of thyrotoxic crisis is discussed: although chlorpromazine, phenobarbitone, corti- 3 . costeroids, guanethidine and reserpine probably played a useful part, it is emphasised that the use $\frac{\circ}{3}$ of these drugs does not render superfluous the use of intravenous iodide; in our patient this 9 appeared to be the most effective agent.

We are very grateful to Dr. L. A. Liversedge, Dr. Donald Longson, Mr. R. H. Martin and Mr. Alan N Nicholson for invaluable help in the management of $\mathrm{N}$ this patient. We also thank Sister K. Murphy and $N$ her nursing staff for their devoted and efficient care $\mathcal{N}$ of this patient, without which she would not have $\omega$ survived.

\section{REFERENCES}

LAHEY, F. H. (1928): The Crisis of Exophthalmic $\stackrel{\oplus}{+}$ Goiter, New Engl. J. Med., 199, 255.

MCQuillan, M. P., Gross, M. and Johns, R. J. ํㅜㅇ (1963): Chlorpromazine-induced Weakness in $\frac{\vec{D}}{\mathbb{D}}$ Myasthenia Gravis, Arch. Neurol. (Chic.), 8, 286. 
MonRo, P. (1963): Treatment of Myasthenia Gravis, Lancet, i, 108.

RobBINS, J. J. and BuRkLe, J. S. (1960): Association of Myasthenia Gravis and Hyperthyroidism, showing Reciprocal Relationship: Report of a Case and Review of the Literature, Ann. intern. Med., 52, 890.
Weaver, J. A., Jones, A., and Smith, R. A. (1956): Thyrotoxic Coma (Apathetic Crisis), Brit. med. J., i, 20.

WEICKHARDT, G. D. and REDMOND, A. J. (1960): Myasthenia Gravis and Hyperthyroidism: Report of Two Cases and Review of the Literature, Ann. intern. Med., 52, 1246.

\title{
APLASTIC ANAEMIA DUE TO PHENYLBUTAZONE
}

\author{
E. A. Cameron, M.B., Ch.B., M.R.C.P.E., \\ Consultant Physician. \\ A. A. EISEN, M.R.C.S., L.R.C.P. \\ Registrar.
}

\author{
L. M. Niranjan, M.B., B.S. \\ House Physician.
}

From Ashington General Hospital, Northumberland.

IT HAS been estimated (Annotation, 1962) that in any given week in Great Britain alone, 100,000 people are taking phenylbutazone. There are several well known side effects from this drug, and a considerable number of cases in which marrow depression has occurred have already been reported (Leonard, 1953; Kersley and Mandell, 1963; Kaplin, 1955; Venning, 1957; Hale and DeGruchy, 1960; Rankin, 1961; Lander and Bonnin, 1962; McCarthy and Chalmers, 1964; Humble, 1964; Woodliff and Dougan, 1964). Our search of the literature has revealed 15 cases of aplastic anaemia in patients taking phenylbutazone; in 7 of these cases the marrow failure proved fatal.

We record the following case of fatal aplastic anaemia because it re-emphasises the possible dangers of this drug and the need for extreme wariness when it is being used.

\section{Case Report}

A 79-year-old widow was admitted to hospital on the 6 th of November, 1964. Pernicious anaemia had been diagnosed in 1954 and had been well controlled with cytamen given every three weeks. About the end of 1963 she had complained of "arthritic pains" in the hands and legs, and her own doctor prescribed phenylbutazone, $100 \mathrm{mg}$. tablets, one thrice daily. In fact she took the tablets rather erratically, so that the total amount taken over a period of 11 months was approximately $10 \mathrm{~g}$. (about 100 tablets). Three weeks prior to admission spontaneous bruises appeared on the right arm, and shortly after she noticed what transpired to be a typical purpuric rash on both lower limbs. Phenylbutazone was stopped on October 14th, 1964.

On admission she was well nourished, rather obese and obviously anaemic, but not jaundiced or cyanosed. The tongue was covered with small purpuric lesions, also noted in other parts of the buccal cavity. There was a one centimetre bruise on the lower lip, which was superficially infected. There was no lymphadenopathy. Pulse regular, $100 / \mathrm{min}$., normal volume; the blood pressure was $130 / 80 \mathrm{~mm}$. Hg. JVP not raised; no sacral or ankle oedema. The heart was not clinically enlarged and heart sounds were normal. The liver and spleen were impalpable. The central nervous system was normal. In the right fundus there were haemorrhages around the disc margin; the left fundus was normal. There was no evidence of peripheral neuropathy or of lateral column involvement as might have occurred in association with her known pernicious anaemia.

Initial Investigations: Hb. 5.6 g. $/ 100 \mathrm{ml}$, RBC $2,000,000 / \mathrm{cu}$. mm. (retics $0.2 \%$ ), PCV 19\%, MCHC $31 \%$, ESR $136 \mathrm{~mm}$./1 hour, WBC 2,100/cu. mm. (Polys. 8\%, Lymphs. 90\%, Lymphoblasts 1\%, Monos. $1 \%)$. Platelets $45,000 / \mathrm{cu}$. mm. Bleeding Time (McFarlane) 24 min., Clotting Time (Capillary) $4 \frac{1}{2}$ min., Prothrombin Activity (Thrombo Test) $100 \%$ of average normal, Direct Coombs Test negative, Serum Iron $157 \mu \mathrm{g} . / 100 \mathrm{ml}$. Blood Group 'A' positive.

Blood film: The blood film showed normal erythrocytes with occasional late normoblasts; an occasional primitive leucocyte was present and agranulocytosis was obvious. Platelets were very sparse.

Sternal Marrow: Sections of the marrow showed $95 \%$ fat with only an occasional island of haemopoietic tissue (Fig. la \& b). These islands were mainly lymphocytes and showed no polymorphonuclear cells or megakaryocytes. Differential count showed a leuco-erythroid ratio of 5 to 1 . The leucopoietic tissue was $75 \%$ lymphocytes with a few lymphoblasts. Primitive cells were not frequent. Erythropoesis was normoblastic with no arrest of maturation. The overall picture was that of aplasia, affecting most severely thrombocytes and granulocytes; to a slightly less degree the erythrocytes. 